oi:10.1520/GTJ20160211 / Vol.40 / No.4 / July 2017 / available online at www.astm.org

Manuscript received August 29, 2016; accepted for publication January 23, 2017; published online May 12, 2017.

1 Geotechnical Dept., MOTA-ENGIL, Engenharia e Construção, Rua Rego do Lameiro, 38, 4300-454 Porto, Portugal

2 CONSTRUCT-GEO, Faculty of Engineering, Univ. of Porto, Rua Dr. Roberto Frias, s/n 4200-465 Porto, Portugal (Corresponding author), e-mail: sara.rios@fe.up.pt (D) http://orcid.org/0000-0002-26251452

${ }^{3}$ Transportation Dept., National Laboratory for Civil Engineering, Avenida do Brasil, 101, 1700-066 Lisboa, Portugal

${ }^{4}$ Polytechnic Inst. of Guarda, Av. Dr. Francisco Sá Carneiro, 50, 6300-559 Guarda, Portugal

${ }^{5}$ Faculty of Engineering, Univ. of Porto, Rua Dr. Roberto Frias, s/n 4200-465 Porto, Portugal
N. Cruz, ${ }^{1}$ S. Rios, ${ }^{2}$ E. Fortunato, ${ }^{3}$ C. Rodrigues, ${ }^{4}$ J. Cruz, ${ }^{1}$ C. Mateus, ${ }^{1}$ and C. Ramos ${ }^{5}$

\section{Characterization of Soil Treated With Alkali-Activated Cement in Large-Scale Specimens}

\section{Reference}

Cruz, N., Rios, S., Fortunato, E., Rodrigues, C., Cruz, J., Mateus, C., and Ramos, C., "Characterization of Soil Treated With Alkali-Activated Cement in Large-Scale Specimens," Geotechnical Testing Journal, Vol. 40, No. 4, 2017, pp. 618-629, http://dx.doi.org/10.1520/GTJ20160211. ISSN 0149-6115

\section{ABSTRACT}

Soil improvement with hydraulic binders is currently used in practice because of the advantages of using the local soil enhancing its geotechnical properties. However, environmental issues related to quicklime applications and carbon-dioxide emissions associated to Portland cement production encouraged the development of new binders. In this work, alkaline-activated cement (AAC) synthetized by fly ash and an alkaline solution was used to stabilize silty sand. The behavior of the treated soil was evaluated performing tests on a physical model and the results were compared to laboratory data to define its compaction, strength, and stiffness properties. Those tests include nuclear density gauge measurements, light falling weight deflectometer tests, and plate load tests, whereas unconfined compression tests with unload-reload cycles and seismic wave measurements were performed at the laboratory. These tests, very common in current geotechnical practice, have proved to be also adequate to quality control and to evaluate the geomechanical properties of this material. The results at 28 days show a significant improvement given by the AAC, but still show some sensitivity to water when flooded. The comparison of results from different tests provided the evolution of stiffness with strain level.

\section{Keywords}

fly ash, alkali-activated cement, soil improvement, physical model, real-scale demonstration, controlledcondition chamber 


\section{Introduction}

Soil improvement techniques are very often required in road and railway track works as a mean to use materials that otherwise could not be applied. In general, the most common techniques for this purpose are cement or lime soil mixtures (Nusit et al. 2015; Jha and Sivapullaiah 2016), but other possibilities have been pursued and promoted, especially when low-cost roads are intended.

This paper presents some test results aimed to study an alternative solution to cement or lime soil mixtures (sometimes difficult to obtain, or even forbidden to produce) to be used as a surface layer of unpaved roads. This solution is based on a soil treatment with an alkali-activated cement (AAC) synthetized with fly ash from coal burning and an alkaline solution made from sodium silicate and sodium hydroxide. The alkaline activation of the ashes previously mixed with the soil creates a set of chemical reactions that generates a particle bonding similar to the soil-cement treatment, but with lower production of carbon dioxide because there is no Portland cement involved, which is known for its high carbon footprint (Worrell et al. 2001).

Following the concept first introduced by Davidovits (1991), this involves the chemical reaction of alumina-silicate oxides with alkali polysilicates, yielding polymeric Si-O-Al bonds (van Jaarsveld et al. 2002). The source materials based on alumino-silicate should be rich in silicon $(\mathrm{Si})$ and aluminum (Al). These could be natural minerals (such as kaolinite, clays, micas, andalousite, spinel, etc.) or by-product materials (such as fly ash, silica fume, slag, rice-husk ash, red mud, etc.). The alkaline liquids are from soluble alkali metals that are usually sodium or potassium based (Wallah and Rangan 2006).

This process can be economic, being at the same time environmentally friendly, as it reduces the carbon dioxide produced and incorporates a waste material. This technology has been applied in other areas of construction (e.g., concrete), but for soil stabilization few studies have been done (Cristelo et al. 2011, 2013; Rao and Acharya 2014; Sukmak et al. 2015; Rios et al. 2016a) and the data presently available in the literature about AAC reports mainly laboratory work using small specimens. Thus, the application of this technique requires further research, particularly when it is applied in low cost roads.

During this research large-scale specimens were constructed under controlled conditions in a large dimension chamber [here designated as a controlled-condition chamber (CCC)] to perform tests at a macro-scale, creating a link between laboratory and industrial working conditions. After construction of the specimens, the evolution of the mixture's mechanical characteristics, under natural curing conditions and after increased water content, was analyzed. These characteristics were determined through in situ tests and the results were compared with others obtained in laboratory tests in small specimens. Furthermore, the evaluation of the difficulties of mixing, spreading, homogenizing, and compacting the mixture at an industrial scale was also important.

Considering the application in low-cost roads, the pavement durability in terms of resilient modulus and permanent deformation evolution would also be necessary, as it has already been completed for other materials (Viana da Fonseca et al. 2013a). However, considering the innovative nature of the soil treatment for which research studies have been conducted, mainly at a laboratory scale, the large-scale approach followed in this study seems more appropriate.

\section{Experimental Setup and Test Program in Physical Model}

\section{CONTROLLED-CONDITION CHAMBER DESCRIPTION}

The large-scale specimens of this research program were constructed in a CCC. This is an adapted metallic container (Fig. 1) that has two cells $\left(2.0 \times 2.0 \times 2.0 \mathrm{~m}^{3}\right)$ divided by a removable separator so that it becomes possible to work in the two cells separately or together in a unique block of $4.0 \times 2.0 \times 2.0 \mathrm{~m}^{3}$. In the present case, the two cells were used together to assure that tests could be performed minimizing any influence of the

FIG. 1

Calibration chamber: (a) model and (b) general view.

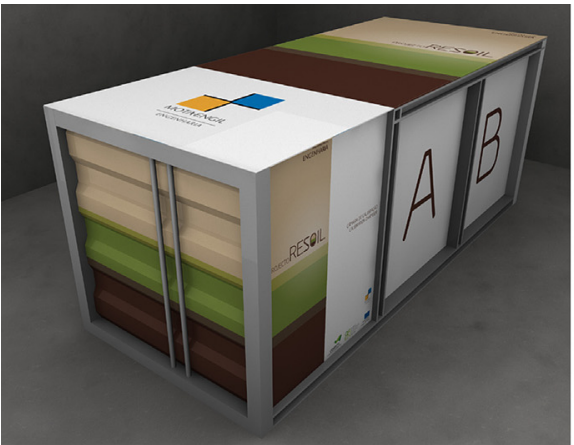

a)

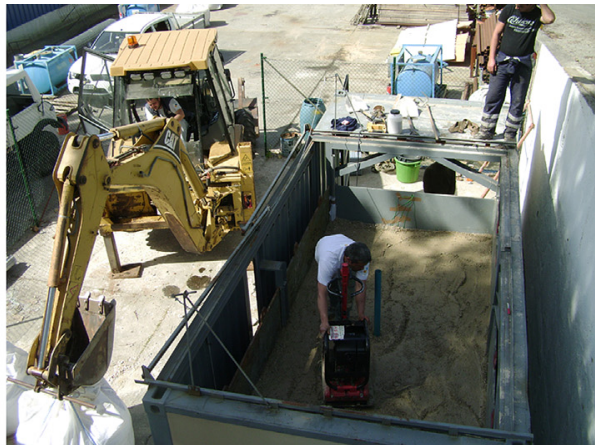

b) 
TABLE 1 Identification of the soil properties.

\begin{tabular}{lcccr}
\hline$<\# 200(\%)$ & Liquid Limit (\%) & Plasticity Index (\%) & Unified Classification (ASTM D2487 2011) & AASHTO Classification (AASHTO 2008) \\
\hline 30.2 & NP & NP & SM & A-2-4(0) \\
\hline
\end{tabular}

container walls. Furthermore, the chamber also contains a small compartment communicating with the cells that allows protected installation and use of sensitive equipment (monitoring, electronic, or other). The great advantage of using equipment such as the CCC is related to the possibility of developing research programs under controlled conditions, as well as testing considerable volumes of material without having significant scale problems.

\section{SOIL AND MIXTURE PRELIMINARY CHARACTERIZATION}

The soil used in this work was a well-graded remolded residual silty sand from granite already studied in detail in its natural and remolded conditions (Viana da Fonseca 2006, 2013b; Cruz 2010). Tables 1 and 2 present the results of identification and compaction tests performed in the remolded soil, as well as the compaction results for the mixture of soil with $20 \%$ of fly ash. It is interesting to note that the addition of fly ash did not change the compaction properties significantly.

Low calcium fly ash, classified as F according to ASTM C618 (2015), was supplied by a coal thermoelectric power plant located in the central part of Portugal. The chemical composition of the fly ash is presented in Table 3.

The alkaline solution was made by combining sodium hydroxide $(\mathrm{SH})$ and sodium silicate (SS) in a ratio of $\mathrm{SS} / \mathrm{SH}=0.5$. The sodium hydroxide was supplied in a $32 \%$ solution that was converted in 5-molal concentration by adding the necessary quantity of water. In a field condition, the use of sodium hydroxide in solution instead of pellets makes the preparation procedures easier with fewer safety concerns because the dissolution of sodium hydroxide pellets in water is a highly exothermic reaction. The sodium silicate was already supplied in a solution with $1.464 \mathrm{~g} / \mathrm{cm}^{3}$ of bulk density at $20^{\circ} \mathrm{C}$, a $\mathrm{SiO}_{2} /$ $\mathrm{Na}_{2} \mathrm{O}$ weight ratio of 2.0 (molar oxide ratio of 2.063), and an $\mathrm{Na}_{2} \mathrm{O}$ concentration in the solution of $13.0 \%$.

\section{CONSTRUCTION OF SOIL LAYERS}

The large specimen was constructed inside the chamber by compacting three soil layers of $30 \mathrm{~cm}$ each; on top of these layers, one layer of treated soil with $20 \mathrm{~cm}$ was placed and compacted. The soil was introduced inside the CCC with a common excavator, and then it was spread so that the surface was roughly at the same height. Because the natural water content was close to the optimum value of the Standard Proctor (15.2\%) no water was added to the soil during the compaction of the non-treated soil layers. The Standard Proctor was adopted as a reference for compaction, instead of the Modified Proctor, because the test was intended to simulate the construction of low cost roads where only the lower energy of compaction is usually available. The compaction was performed with a vibrating plate with $500 \times 500$ $\mathrm{mm}^{2}$ of area and $115 \mathrm{~kg}$ of weight actuated by a diesel engine, during approximately half an hour (as calibrated in the first layer) covering, as much as possible, the whole exposed area.

For the treated layer, the soil and $20 \%$ of fly ash (defined as a percentage of the dry soil weight) were first mixed in a concrete mixer. Then, the alkaline solution was added so that the liquid content (ratio between the alkaline solution and solids) was $19 \%$, and the mixture was mixed again until complete homogenization was achieved. This liquid content, corresponding to a real water content of around $14.7 \%$, was adjusted taking into account the soil water content before mixing (around $8 \%$ ) because it was not possible to dry completely this amount of soil in a reasonable time. Care was taken in this mixing process to avoid localized particle agglomerations. The mixture was then moved to a big bag and transported with a crane to the CCC to be spread and compacted by the vibrating plate (Fig. 2). The same compaction time and procedures of the previous soil layers were adopted in this case. The level of homogeneity can be observed in the photos taken at the end of the experience (after testing) when the front walls of CCC were removed (Fig. 3). Measurements taken at this time confirmed the thicknesses of the different layers and revealed visual homogeneity and a notable difference in the cohesion of treated and untreated material when hand squeezed.

TABLE 2 Compaction tests results in the soil.

\begin{tabular}{|c|c|c|c|c|c|c|}
\hline \multirow[b]{2}{*}{ Material } & \multicolumn{2}{|c|}{ Standard Proctor } & \multicolumn{2}{|c|}{ Modified Proctor } & \multirow{2}{*}{$\frac{\mathrm{CBR} \text { at } 95 \%}{(\%)}$} & \multirow{2}{*}{$\frac{\text { Expansion at } 95 \%}{(\%)}$} \\
\hline & $\gamma_{d \max }{ }^{\mathrm{a}}\left(\mathrm{kN} / \mathrm{m}^{3}\right)$ & $w_{\text {opt }} \mathrm{b}(\%)$ & $\gamma_{d \max }\left(\mathrm{kN} / \mathrm{m}^{3}\right)$ & $w_{\text {opt }}(\%)$ & & \\
\hline Soil & 17.58 & 15.2 & 18.96 & 12.0 & 15.0 & 1.0 \\
\hline Soil $+20 \%$ of fly ash & 17.44 & 15.8 & 18.90 & 12.0 & 12.0 & 1.0 \\
\hline
\end{tabular}

$\mathrm{a}_{\gamma_{\text {max }}}=$ maximum dry unit weight.

${ }^{b} w_{\text {opt }}=$ optimum water content. 
TABLE 3 Composition of the fly ash.

\begin{tabular}{lccccccccccc}
\hline Element & $\mathrm{SiO}_{2}$ & $\mathrm{Al}_{2} \mathrm{O}_{3}$ & $\mathrm{Fe}_{2} \mathrm{O}_{3}$ & $\mathrm{CaO}$ & $\mathrm{K}_{2} \mathrm{O}$ & $\mathrm{TiO}_{2}$ & $\mathrm{MgO}$ & $\mathrm{Na}_{2} \mathrm{O}$ & $\mathrm{SO}_{3}$ & $\mathrm{Others}$ \\
\hline wt. \% & 54.84 & 19.46 & 10.73 & 4.68 & 4.26 & 1.40 & 1.79 & 1.65 & 0.7 & 0.5 \\
\hline
\end{tabular}

\section{PHYSICAL MODEL TESTING PROGRAM}

The program comprised fundamentally two types of tests: tests for compaction quality control to verify the required characteristics of each layer; and deformability tests to evaluate the stiffness evolution because of treatment, curing time, and variation of water content. Furthermore, this experimental program was also intended to check the adequacy of the testing equipment and procedures commonly used in this type of work to the soil treated with AAC. Compaction control was performed by means of a nuclear density gauge, whereas the evaluation of the soil stiffness was achieved by dynamic and static load tests through the light falling weight deflectometer (LFWD) and the plate load test (PLT), respectively.

Measurements with the nuclear density gauge (Fig. 4a) followed ASTM D6938 (2015), which was first calibrated with a sand bottle test in one central point.

LFWD tests (Fig. 4b) were performed according to ASTM E2583 (2011) with a plate of $30 \mathrm{~cm}$ corresponding to $200 \mathrm{kPa}$ of applied stress. The deflections were measured in three geophones located at $0 \mathrm{~cm}, 30 \mathrm{~cm}$, and $60 \mathrm{~cm}$ from the plate center.

The plate load tests (Fig. 4c) were performed according to the NF P94-117-1 (AFNOR 2000), although using a plate of $30 \mathrm{~cm}$ diameter instead of $60 \mathrm{~cm}$ as established in the respective standard. The stress bulb of a circular plate of $60 \mathrm{~cm}$ would cover the three untreated layers, and it would probably feel some influence of the rigid base of the chamber, which is why the plate diameter was reduced.

The equivalent deformation modulus on the surface of the model, $E$, was calculated using the Boussinesq theory by the following expression:

$$
E=k \cdot\left(1-v^{2}\right) \cdot d \cdot \frac{p}{\delta}
$$

where:

$k=1$ in the case of LFWD (flexible plate) and $=\pi / 4$ for PLT (rigid plate),

$v=$ the Poisson ratio (assumed 0.35),

$d=$ the plate diameter,

$p=$ vertical pressure, and

$\delta=$ the settlement of the plate.

In the tests with LFWD, this displacement is measured with the geophone located at the center of the plate. In the PLT, the displacement considered in the modulus calculation was measured on the second load cycle and the maximum vertical stress was $250 \mathrm{kPa}$ in the first load cycle and $200 \mathrm{kPa}$ in the second, as established in the standard.

In Table 4, the whole test plan is presented indicating the tests performed at each layer, and corresponding date (related to construction process) and location. For interpretation purposes, it was decided that all the tests would be, as much as possible, in the same location in all the layers, with the spatial distribution represented in Fig. 5. As for the tests at the 28th and 29th curing day, some changes had to be introduced because it was not possible to perform density tests at the same location.

In this context, nuclear density gauge tests were performed in all four layers to measure the obtained compaction level, PLT tests were executed at the third soil layer and on the top of treated layer, immediately after compaction, and LFWD tests were done in the second soil layer and in the treated layer at 7 , 14,21 , and 28 days. During curing, it was decided to use only

FIG. 2 Test setup: (a) mixing materials, (b) deposition in the CCC, and (c) compacting the layers.

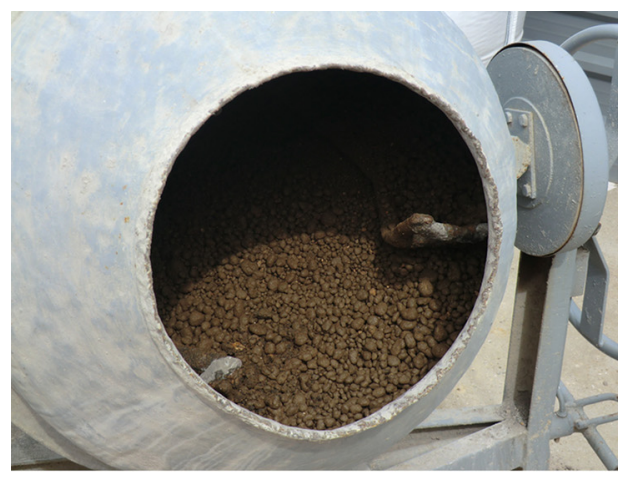

a)

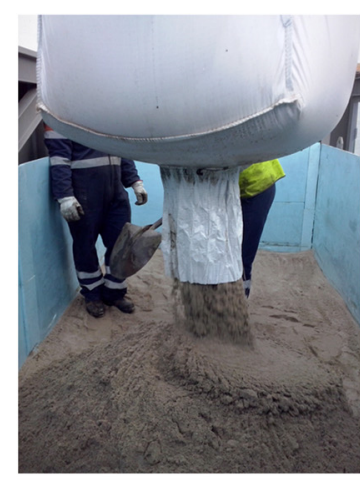

b)

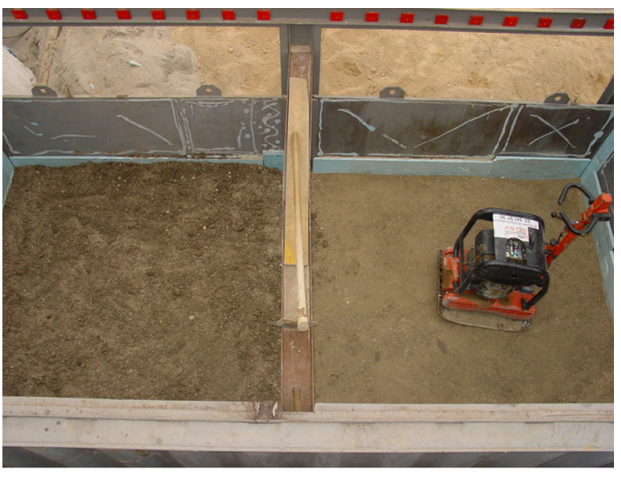

c) 


\section{FIG. 3}

CCC sample: (a) view of specimen after removing the front walls and (b) dismantling the sample.

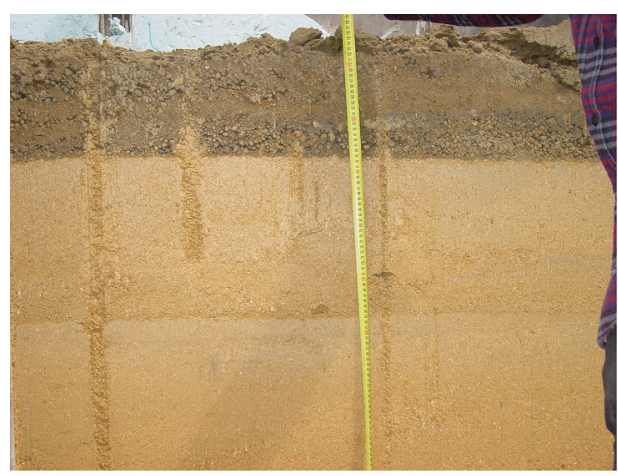

a)

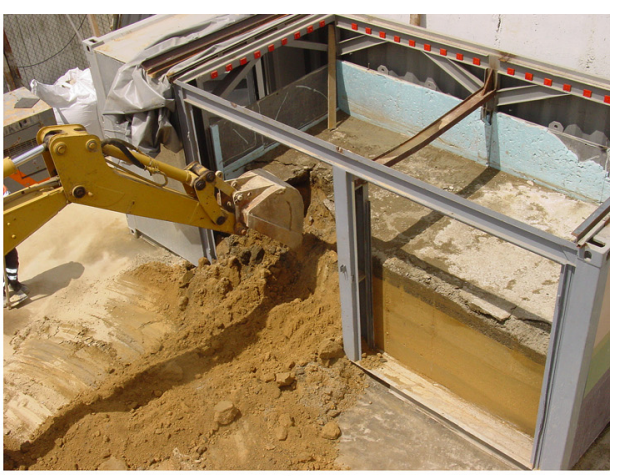

b) the LFWD tests because of their low cost and fast use (Stamp and Mooney 2013; Grasmick et al. 2015).

At the 28th curing day, after the set of programmed tests, the model was flooded with water to evaluate its properties when subjected to intense rain and tested (LFWD) again the day after (29th). Because of its low permeability, the water did not infiltrate immediately taking almost $1 \mathrm{~h}$ to infiltrate $5 \mathrm{~cm}$ height of accumulated water. After this, the model was flooded with $30 \mathrm{~cm}$ height of water that was left overnight to infiltrate (Fig. 6).

\section{Results}

\section{COMPACTION CONTROL RESULTS}

The results obtained with the nuclear density gauge in terms of water content and dry unit weight are presented in Table $\mathbf{5}$ for the three soil layers, as well as for the treated layer at the day of compaction. Measurements were taken at the surface and at $15-\mathrm{cm}$ depth for each layer and so the results presented for each layer are the average of those measurements. The results obtained in the center points of the model were considered more representative because the walls might affect the results obtained in the points closer to the container. For that reason, the average values presented in Table 5 only include the results at those locations. The degree of compaction is also presented calculated by the percentage of the standard proctor maximum dry unit weight presented in Table 2 for the soil and for the mixture of soil and $20 \%$ of fly ash.

The dry unit weights changed between 15 and $16 \mathrm{kN} / \mathrm{m}^{3}$ in the non-treated layers being slightly higher in the treated layer. This corresponds to degrees of compaction around $90 \%$ in the soil and $95 \%$ in the treated layer. Because the compaction procedures used on the non-treated and treated layers have been the same, this difference may be because of the characteristics of the liquid phase in the treated layer (more viscous than water) and in the higher fines content (with the addition of fly ash).

The water content varied between $16 \%$ and $17 \%$ in the soil layers (slightly higher than the optimum Standard Proctor water content, $15.2 \%$ ) being significantly lower in the treated layer (13\%). It should be noted that the treated layer was prepared to have a water content of $14.7 \%$, as indicated above, that became slightly reduced because of soil drying during the preparation of the mixture and because of the heat generated by the exothermic reaction between the activator solution and the fly ash.

For all of these values, the coefficient of variation $(\mathrm{CV})$ was low except for the water content of the treated layer that presented a CV of 0.11 .

At the CCC, curing was performed at the ambient temperature of that period, which fluctuated between $10^{\circ} \mathrm{C}$ and $16^{\circ} \mathrm{C}$.

FIG. 4 Aspects of the tests: (a) nuclear density gauge, (b) LFWD, and (c) PLT.

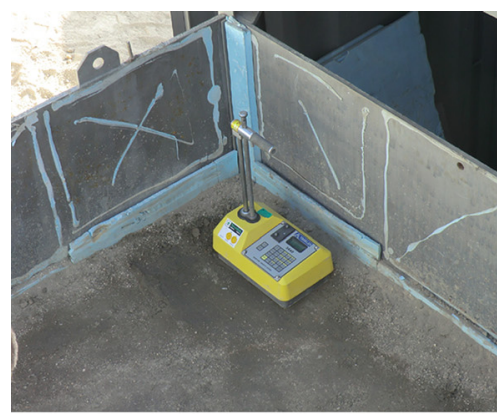

a)

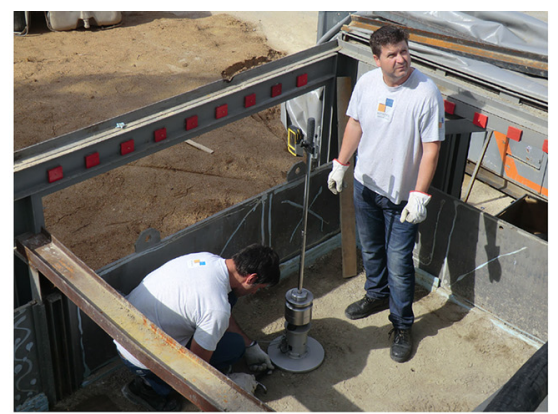

b)

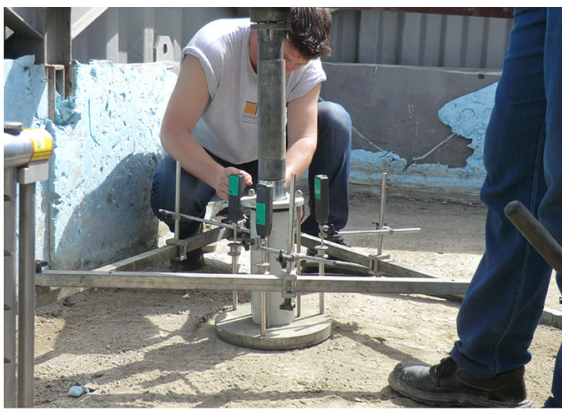

c) 
TABLE 4 Tests performed in each layer of the model (see Fig. 5).

\begin{tabular}{lccc}
\hline & Stage & $\begin{array}{c}\text { Days After } \\
\text { Construction }\end{array}$ & $\begin{array}{c}\text { Nuclear Density } \\
\text { Gauge (NDG) }\end{array}$ \\
\hline I & First soil layer & 0 day & $\begin{array}{c}\text { Plate Load } \\
\text { Tests (PLTs) } \\
\text { Deflectometer (LFWD) }\end{array}$ \\
II & Second soil layer & 0 day & N1, N2, N3, N4, N5, N6, N7, N8 \\
III & Third soil layer & 0 day & N1, N2, N3, N4, N5, N6, N7, N8 \\
IV & Treated soil after compaction & 0.5 day & N1, N2, N3, N4, N5, N6, N7, N8 \\
V & Treated layer during curing & 7th, 14th, and 21st day & P1, F2, F3, F4 \\
VI & Treated layer after 28 days of curing & 28th day & N1, N2, N3, N4, N5, N6, N7, N8 \\
VII & Treated layer after flooding & 29th day & N6, N8, N9, N10, N11, N12, N13, N14 \\
\hline
\end{tabular}

\section{EQUIVALENT DEFORMATION MODULUS ON THE TOP OF THE LAYERS}

Fig. 7 shows the average value of the equivalent deformation modulus measured with LFWD and PLT in the points indicated in Fig. 5 at each stage.

Considering the LFWD values, it is possible to conclude that there is a significant increase of the deformation modulus measured on the top of the model because of the treatment of the surface layer and throughout the curing process of this layer. Furthermore, it can be concluded that the induced flooding in the model caused a significant decrease in the deformation modulus measured at the top of the treated layer, so that the value measured on the 29 th day is about $70 \%$ of the one that was measured before soaking (28th day). Another interesting detail observed in these results is that between the seventh and 28th day the deformation modulus values have not changed significantly (160 MPa to $177 \mathrm{MPa})$. It is also noticed that at 21 days the mixture has reached the maximum strength, which is followed by a very slight decrease until the 28th day of curing. However, these small changes are within the range of values associated to the test error. In Table 6, the values obtained in this work are compared with LFWD moduli available in the literature for soil stabilized with a traditional binder such as Portland cement. Although the obtained values are within the range published in the literature, it should be noted that the

FIG. 5 Location plan of the tests performed.

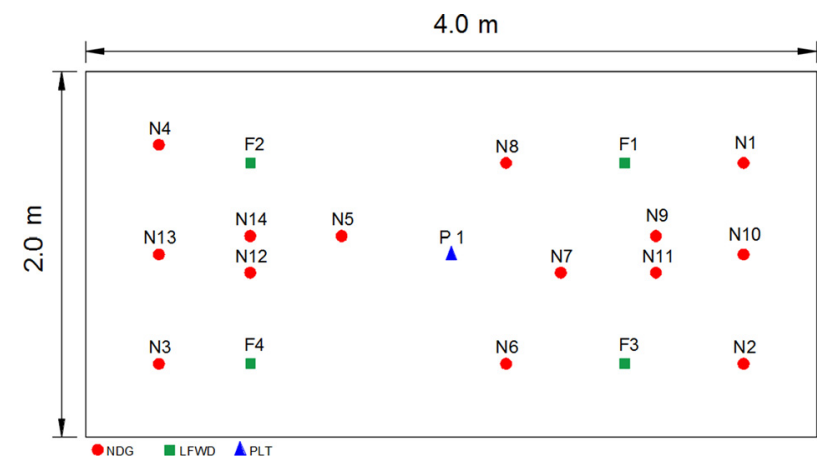

cement dosage and compaction conditions have a very high influence on the obtained moduli.

The values of deformation modulus obtained with PLT and LFWD (average value) in the soil layers during construction were $32 \mathrm{MPa}$ and $20 \mathrm{MPa}$, respectively. The ratio between these two values is in agreement with the results obtained on different types of materials using similar methods (FGSV 2009). The PLT result obtained on the top of the treated layer at $1 / 2$ day of curing is already twice the value for the non-treated layer. Although there is an increase in the degree of compaction of the treated layer that certainly implies stiffness increase, this cannot solely explain such an evolution, which might be related to the treatment.

In a layered system such as the one built in the physical model it is not possible to directly obtain the deformation modulus of each layer from the load tests. To estimate the stiffness modulus of the non-treated and treated layer, a back-analysis procedure was developed to compare the deformations obtained in the three geophones used in the tests with those calculated in a numerical model. For that purpose, the commercial software ELSYM was used, which is based on the multilayered system theory (Brown 1996). To build the structural model, the layer thicknesses were considered, the constitutive behavior of the materials was assumed linear elastic, and the load was applied by a $300 \mathrm{~mm}$ diameter plate.

An iterative process was then developed to determine the deformation modulus of the treated layer, to obtain deflections similar to those measured in the three geophones on the 29th day, and considering a deformation modulus of the underlying non-treated soil layer similar to the one measured during construction. In general, a good approximation was obtained between the deformations calculated by the numerical model and the values measured by the geophones (Fig. 8). From this study, the deformation modulus for the untreated soil was estimated to be around $30 \mathrm{MPa}$. This value is slightly higher than that obtained in the second soil layer with LFWD (20 MPa) probably because of the following reasons: this layer has a smaller density; and other layers were constructed and compacted above improving the overall stiffness because of the 


\section{FIG. 6}

Aspects of the model after flooding: (a) top view of the chamber immediately after watering showing the accumulated water, and (b) view of the treated layer on the following day showing the "cake" generated at the surface of the treated layer.

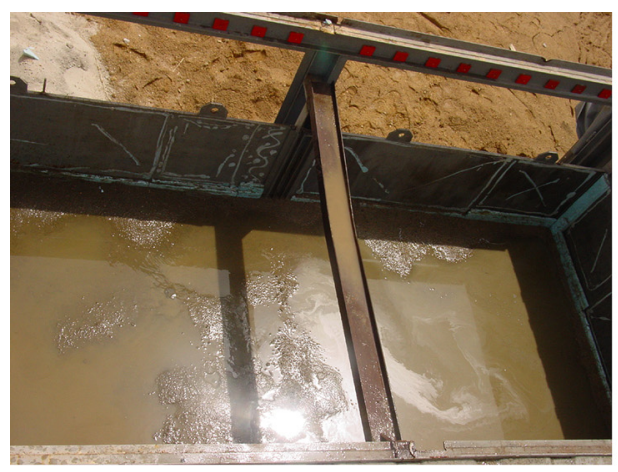

a)

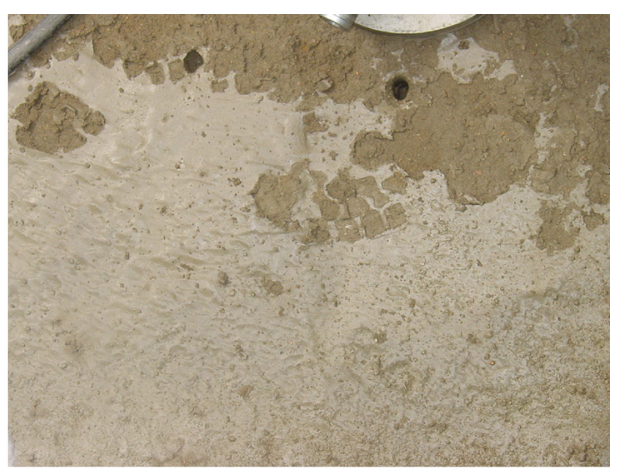

b) increase in the average stress state. The treated layer stiffness estimated in this back-analysis was around $1300 \mathrm{MPa}$. The calculated value of vertical strain of the treated layer was $0.7 \times 10^{-4}$.

\section{Laboratory Test Results}

A set of tests was performed in laboratory to characterize the mixtures and compare the values with those obtained in the tests performed on the physical model. Six equal specimens were molded according to the procedure described in ASTM D1632 (2007), trying to reproduce the mixture characteristics of the treated layer done in the calibration chamber. The properties of the mixture are defined in Table 7, where SS means sodium silicate and $\mathrm{SH}$ stands for sodium hydroxide. The values of water content and dry unit weight used to mold the specimens were taken from the nuclear density gauge results on the treated layer considered representative of the physical model conditions. The liquid content corresponds to the ratio of the quantity of activator solution (water plus SS and $\mathrm{SH}$ ) to the quantity of solids (soil and fly ash). A soil specimen with $16 \%$ of water content and $17 \mathrm{kN} / \mathrm{m}^{3}$ of dry unit weight was also molded for comparison purposes.

During the curing period (at laboratory temperature around $20^{\circ} \mathrm{C}$ ), seismic wave propagation times $\left(t_{P}\right.$ and $t_{S}$, for $\mathrm{P}$ and $\mathrm{S}$ waves, respectively) were measured at $3,7,14,21$, and 28 days, using ultrasonic transducers. The equipment consists of a pair of compression transducers and a pair of shear transducers, a pulse waveform generator, and data acquisition unit equipped with an amplifier connected to a personal computer with specific software to operate as an oscilloscope. Based on the propagation times evaluated with a time domain approach (Viana da Fonseca et al. 2009; Rios et al. 2016b), the wave velocities $\left(V_{P}\right.$ and $V_{S}$, respectively for $\mathrm{P}$ and $\mathrm{S}$ waves) were determined dividing the height of the specimen by the time. From the results of the seismic wave's velocities, the evolution of the dynamic Young's Modulus $\left(E_{0}\right)$ was obtained according to the following elasticity theory equations:

$$
\begin{gathered}
G_{0}=\rho V_{S}^{2} \\
v=\frac{\left(\frac{V_{P}}{V_{S}}\right)^{2}-2}{2\left(\frac{V_{P}}{V_{S}}\right)^{2}-2} \\
E_{0}=2 G_{0}(1+\nu)
\end{gathered}
$$

where:

$G_{0}=$ the maximum shear modulus, and

$v=$ the Poisson's ratio.

The dynamic Young's modulus results obtained in three of the six specimens of treated soil (Fig. 9) indicate a significant evolution, almost linear, of the stiffness along the curing time, reaching about $3000 \mathrm{MPa}$ after 28 days of curing. Unfortunately, it was not possible to obtain the dynamic Young's modulus of

\begin{tabular}{|c|c|c|c|c|c|c|c|c|c|}
\hline & \multicolumn{3}{|c|}{ Water Content (\%) } & \multicolumn{3}{|c|}{ Dry Unit Weight $\left(\mathrm{kN} / \mathrm{m}^{3}\right)$} & \multicolumn{3}{|c|}{ Degree of Compaction (\%) } \\
\hline & Average & Standard Deviation & $\mathrm{CV}$ & Average & Standard Deviation & $\mathrm{CV}$ & Average & Standard Deviation & $\mathrm{CV}$ \\
\hline Treated layer & 13.2 & 1.5 & 0.11 & 16.5 & 0.2 & 0.01 & 94.6 & 1.3 & 0.01 \\
\hline Third soil layer & 17.6 & 1.0 & 0.06 & 16.2 & 0.7 & 0.05 & 92.2 & 4.1 & 0.04 \\
\hline Second soil layer & 16.4 & 1.1 & 0.07 & 15.5 & 0.4 & 0.03 & 88.4 & 3.1 & 0.03 \\
\hline First soil layer & 16.0 & 0.7 & 0.05 & 15.8 & 0.2 & 0.02 & 90.2 & 1.4 & 0.01 \\
\hline
\end{tabular}
the untreated soil specimen because the ultrasonic transducers

TABLE 5 Water content, dry unit weight, and degree of compaction obtained in each layer. 
FIG. 7 LFWD and PLT deformation modulus evolution with curing time.

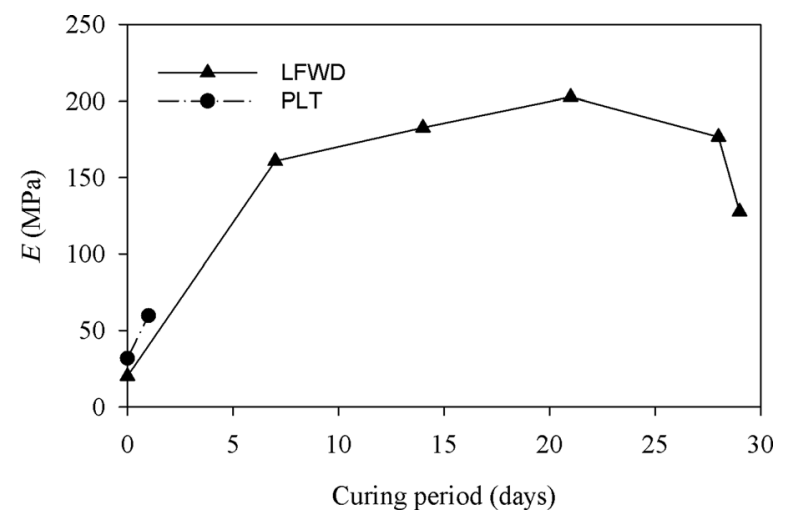

were not able to perceive the signal. This is probably because of the minimum frequency available of $24 \mathrm{kHz}$, which may be too high for an uncemented soil. For comparison purposes, results from a soil-cement specimen made by mixing a silty sand (very similar to the one tested in this paper) and $2 \%$ of cement content (Amaral et al. 2011) are presented in the same figure. Besides the cement dosage, which is not directly comparable with the AAC, the soil-cement evolution generally follows a hyperbolic trend stabilizing at around 28 days, conversely to the continuous evolution shown by the mixtures treated with AAC as recognized in Rios et al. (2016a) for strength and in Rios et al. (2016b) for stiffness.

After these evaluations, all specimens were submitted to unconfined compression tests, according to ASTM D1633 (2007). The specimens were tested at different curing times and conditions as expressed in Table 8. The first three specimens were tested in the same way for reproducible results; S4 intends to simulate the flooding that occurred in the CCC, whereas S5 and S6 were prepared to evaluate the influence of the water submersion during curing (LCPC 2000). The tests were performed using an automatic load frame with displacement control at a speed of $0.05 \mathrm{~mm} / \mathrm{min}$. During the tests, two small unload-reload cycles were performed, one at $200 \mathrm{kPa}$ and the other at $25 \%$ of the expected maximum strength, where the first stress level was selected to simulate the pressure used in the LFWD. The local strain was measured by means of Hall effect transducers (Fig. 10a), allowing a precise evaluation of the axial deformation and derived unload-reload stiffness in the cycles (Clayton et al. 1989; Viana da Fonseca et al. 2013b).

TABLE 6 Comparison of LFWD moduli obtained in the literature.

\begin{tabular}{lccc}
\hline$E_{\text {LFWD }}(\mathrm{MPa})$ & Age (Days) & Type of Soil & References \\
\hline 177 & 28 & Silty sand with AAC & This work \\
$125-175$ & 28 & Silty clay with cement & Nazzal et al. (2007) \\
50 & 28 & Silty clay with lime & Nazzal et al. (2007) \\
$326-527$ & 7 & Cemented clay & Alshibli et al. (2005) \\
\hline
\end{tabular}

FIG. 8 Back-analysis of the data for the LFWD obtained at point F2 according to Fig. 5.

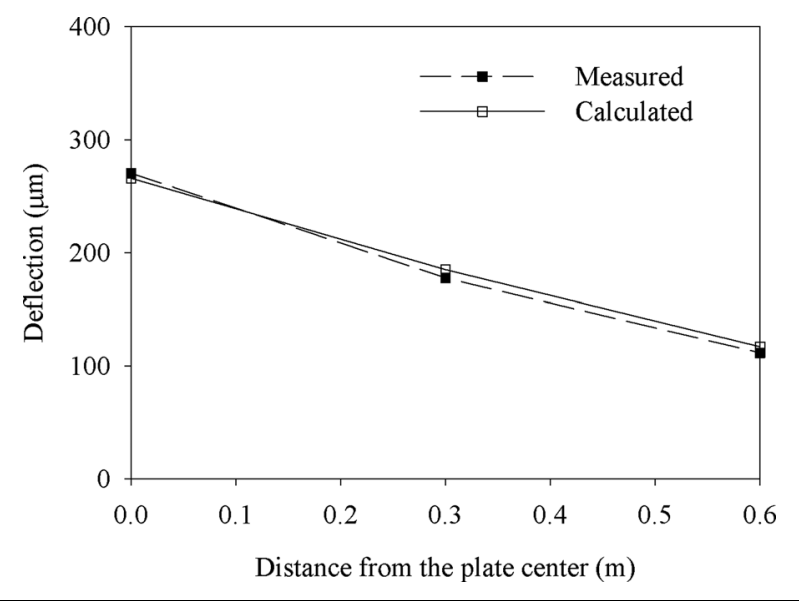

The average value of unconfined compression strength at 28 days (about $1250 \mathrm{kPa}$ ) presented in Fig. 10b (S1, S2, and S3) indicated that the molding procedure provided reproducible specimens and therefore representative results. For that reason, at the other curing times and conditions, only one specimen was tested for each condition. The soil unconfined compression strength is also plotted for comparison, revealing that it is about 33 times less than the treated soil strength.

When a treated specimen with 28 curing days is submerged in water for 1 day (S4), its strength drops around $20 \%$ in relation to a similar specimen with normal curing (S3). However, when the specimen is tested after 28 days of normal curing and 32 days of immersion (S5), its strength only drops $6 \%$ in relation to a specimen with normal curing (S6). This indicates that the long-term strength is only slightly influenced by the curing conditions, conversely to the short-term strength. This is probably because of a strength recovery during curing, reducing the impact of the water submersion on the strength of the specimen.

As shown in the inset of Fig. 10c the hysteric loop was not very significant, and the unload-reload modulus $\left(E_{\mathrm{ur}}\right)$ was obtained by calculating the slope of the line that passes in the two extreme points of the hysteric loop. For the first three specimens, the first and second cycles gave similar $E_{\text {ur }}$ values, which varied between $1200 \mathrm{MPa}$ and $2000 \mathrm{MPa}$, whereas the average axial strain is around $10^{-4}$.

TABLE 7 Mixture characteristics.

Mixture Characteristics

\begin{tabular}{lc}
\hline Fly ash & $20 \%$ \\
SH concentration & 5 molal \\
SS/SH & 0.5 \\
Liquid content $w_{L}(\%)$ & 16 \\
Dry unit weight $\gamma_{d}\left(\mathrm{kN} / \mathrm{m}^{3}\right)$ & 17 \\
\hline
\end{tabular}


FIG. 9 Young's modulus $\left(E_{0}\right)$ evolution with curing time until 28 days.

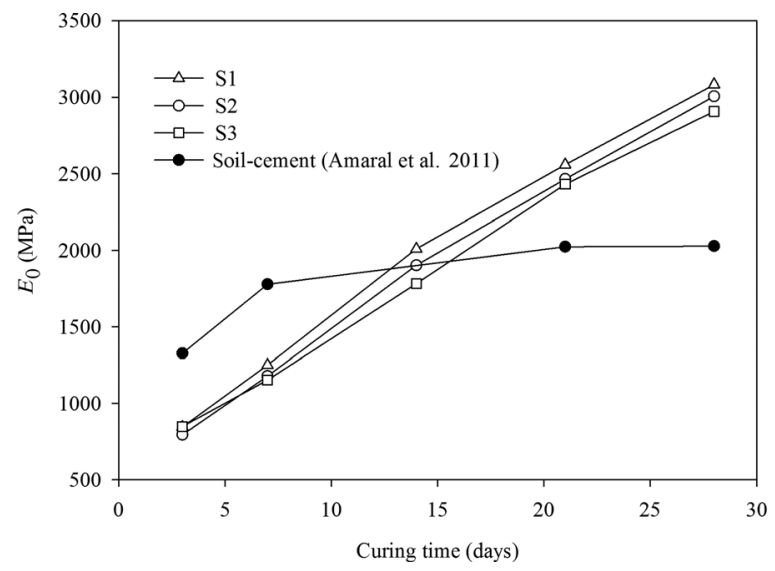

TABLE 8 Curing conditions of the specimens.

\begin{tabular}{lcc}
\hline Specimen & Curing Condition & $\begin{array}{c}\text { Testing } \\
\text { Curing Time }\end{array}$ \\
\hline S1 & Normal curing $^{\mathrm{a}}$ & 28 \\
S2 & Normal curing & 28 \\
S3 & Normal curing & 28 \\
S4 & Normal curing during 28 days & 29 \\
S5 & and 1 day of immersion & 60 \\
& Normal curing during 28 days & \\
S6 & and 32 days of immersion & 60 \\
\hline
\end{tabular}

${ }^{a}$ Normal curing corresponds to a curing in a controlled temperature room at $20^{\circ} \mathrm{C}$.
The stiffness evaluation is more sensitive to small inhomogeneity in the specimens and, consequently, the difference between the three specimens in terms of strength is much lower than the difference in stiffness. However, those differences are not significant and so the molding procedure can be considered adequate to produce reproducible specimens. The other specimens did not provide reliable estimation of the deformation modulus because of some vibration in the load frame that caused a small irregularity in the stress-strain curve.

In the course of this project, a preliminary study was performed where the effect of immersion during curing on the unconfined compression strength of two different mixtures compositions was studied (Fig. 11a). In the case of specimens tested at 28 days, immersion was performed at 7 days of curing, whereas for the specimens tested at 60 days, immersion was at 28 days. The results presented in Fig. 11b confirm the tendency of those in Fig. 10b where it was noted that an early-age immersion had a significant effect on the final strength, whereas immersion at a later stage had a minor or null effect on the final strength.

The strain level involved in the seismic wave measurements is very small (lower than $10^{-5}$ according to Camacho-Tauta et al. 2015), and so the dynamic Young's modulus $\left(E_{0}\right)$, which varied between 2900 and $3080 \mathrm{MPa}$, can be considered the maximum value that can be achieved in this material. Taking into account the different strain values reached in each test, some difference is expected in the deformation moduli because of the well-known stiffness degradation with strain (Tatsuoka et al. 1994; AnhDan et al. 2002). In this case, the $E_{\text {ur }}$ has resulted in approximately half of the $E_{0}$, indicating that the stiffness degradation curve is very steep as typically happens in cemented soils (Leroueil and Vaughan 1990; Viana da Fonseca et al. 1997; Sharma and Fahey 2003).

FIG. 10 Unconfined compression strength tests: (a) test setup, (b) strength values, and (c) unload-reload modulus ( $E_{\text {ur }}$ ) with example of its determination.

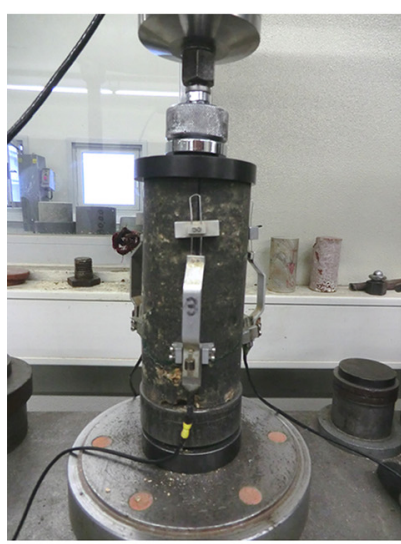

a)

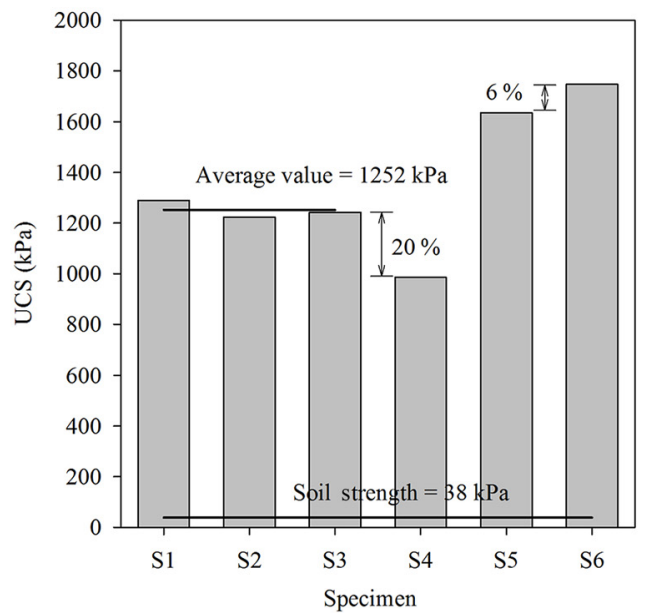

b)

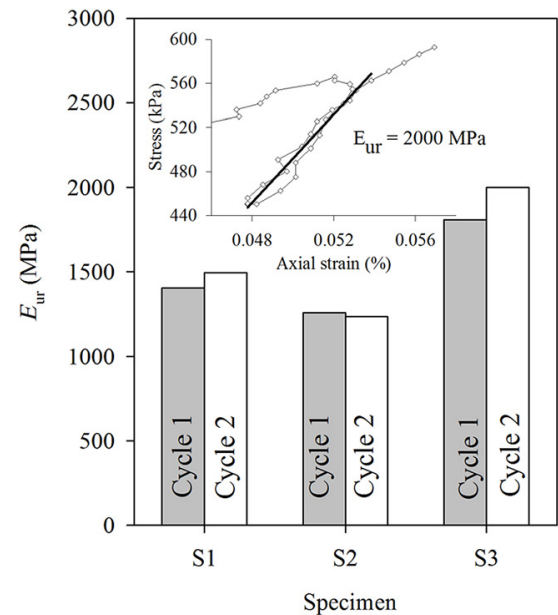

c) 
FIG. 11 Effect of immersion during curing on the unconfined compression strength of two different mixtures: (a) mixtures characteristics and (b) unconfined compression strength results.

\begin{tabular}{l|cc} 
Mixture characteristics & Mixture X & Mixture Y \\
\hline Fly ash & $10 \%$ & $10 \%$ \\
SH concentration & 7.5 molal & 7.5 molal \\
SS/SH & 0.5 & 1 \\
Liquid content $w_{L}(\%)$ & 8 & 8 \\
Dry unit weight $\gamma_{d}\left(\mathrm{kN} / \mathrm{m}^{3}\right)$ & 19.92 & 19.92
\end{tabular}

a)

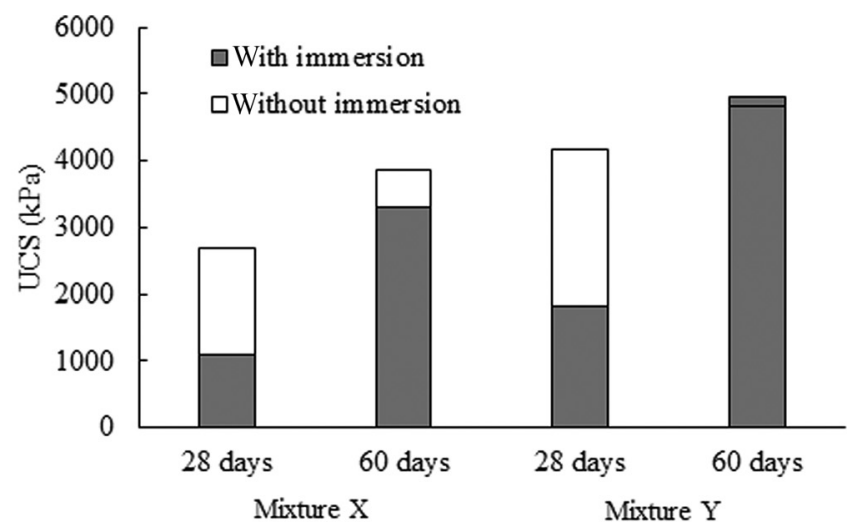

b)

\section{Conclusions}

In this paper, a stabilized soil with AAC was evaluated by field tests using a CCC and by laboratory tests. The evolution with time of the mixtures stiffness was very important both in the treated layer of the physical model, measured with LFWD, and in the laboratory specimens, evaluated by seismic wave velocities.

The treated layer exhibited a deformation modulus two times higher than the untreated soil, only half a day after compaction, which may be because of the higher degree of compaction of this layer when compared to the untreated soil layers, but also to the treatment itself. After 14 days of curing, the equivalent deformation modulus on the surface of the treated layer measured with LFWD improved up to $183 \mathrm{MPa}$ from the $20 \mathrm{MPa}$ obtained for the untreated soil, reflecting the improvement given by the treatment. The back-analyses of the layered system concluded that the deformation modulus of the treated soil is about $1300 \mathrm{MPa}$.

The flooding of the physical model performed on the 29th day had a significant effect on equivalent modulus measured on top of the treated layer. However, the results after flooding were significantly higher (six times more) than those obtained on the top of the soil without treatment.

The dynamic Young's modulus measured on laboratory specimens of treated soil reached about $3000 \mathrm{MPa}$, after 28 days of curing. The unload-reload modulus measured on these specimens during the unconfined compression tests varied between 1200 and $2000 \mathrm{MPa}$.

The unconfined compression strength showed that the soil strength was improved about 33 times by the treatment, taking into account the value measured after 28 days of curing. The long-term unconfined compression strength was only slightly influenced by the curing conditions in contrast to the short-term strength.
Laboratory and physical model tests results indicate different stiffness values, which should be associated to distinct curing conditions between lab and CCC and to the strain levels involved in those tests.

Finally, the installed apparatus (CCC) confirmed the considerable benefits at relatively low cost of using such equipment to perform tests in a soil stabilized with AAC, extending the information of laboratory results, and obtaining values of equivalent deformation modulus that are useful to quality control of construction works.

\section{ACKNOWLEDGMENTS}

This work was executed under the project ECOSOLO (reference FCOMP-01-0202-FEDER-038899) and funded by the European Fund for Regional Development (FEDER) through the Operational Program for Competitiveness Factors (POFC) of the National Strategic Reference Framework (QREN) on the scope of the incentive system for research and technological development. The writers acknowledge the company Pegop - Energia Eléctrica SA, which runs the thermoelectric power plant of Pego, for the supply of fly ash; and the MCTES/FCT (Portuguese Science and Technology Foundation of Portuguese Ministry of Science and Technology) for their financial support through the SFRH/BPD/85863/2012 scholarship, which is cofunded by the European Social Fund by $\mathrm{POCH}$ program, and to the project CONSTRUCT (POCI-01-0145-FEDER-007457) funded by COMPETE 2020.

\section{References}

AASHTO, M145-91, 2008, Standard Specification for Classification of Soils and Soil-Aggregate Mixtures for Highway Construction Purposes, American Association of State and Highway Transportation Officials, Washington, DC. 
AFNOR, NF P94-117-1, 2000, Plate Test Static Deformation Module $\left(E V_{2}\right)$, Part 1, Association Française de Normalisation, Paris.

Alshibli, K., Abu-Farsakh, M., and Seyman, E., 2005, "Laboratory Evaluation of the Geogauge and Light Falling Weight Deflectometer as Construction Control Tools," J. Mater. Civil Eng., Vol. 17, No. 5, pp. 560-569, http:// dx.doi.org/10.1061/(ASCE)0899-1561(2005)17:5(560)

Amaral, M. F., Viana da Fonseca, A., Arroyo, M., Cascante, G., and Carvalho, J., 2011, "Compression and Shear Wave Propagation in Cemented-Sand Specimens," Geotech. Lett., Vol. 1, No. 3, pp. 79-84, http://dx.doi.org/10.1680/ geolett.11.00032

AnhDan, L. Q., Koseki, J., and Sato, T., 2002, "Comparison of Young's Moduli of Dense Sand and Gravel Measured by Dynamic and Static Methods," Geotech. Testing J., Vol. 25, No. 4, pp. 349-368, http://dx.doi.org/10.1520/GTJ11290J. ISSN 0149-6115

ASTM C618, 2015, Standard Specification for Coal Fly Ash and Raw or Calcined Natural Pozzolan for Use in Concrete, ASTM International, West Conshohocken, PA, www.astm.org

ASTM D1632, 2007, Standard Practice for Making and Curing Soil-Cement Compression and Flexure Test Specimens in the Laboratory, ASTM International, West Conshohocken, PA, www.astm.org

ASTM D1633, 2007, Standard Test Methods for Compressive Strength of Molded Soil-Cement Cylinders, ASTM International, West Conshohocken, PA, www.astm.org

ASTM D2487, 2011, Standard Practice for Classification of Soils for Engineering Purposes (Unified Soil Classification System), ASTM International, West Conshohocken, PA, www.astm.org

ASTM D6938, 2015, Standard Test Method for In-Place Density and Water Content of Soil and Soil-Aggregate by Nuclear Methods (Shallow Depths), ASTM International, West Conshohocken, PA, www.astm.org

ASTM E2583, 2011, Standard Test Method for Measuring Deflections With a Light Weight Deflectometer (LWD), ASTM International, West Conshohocken, PA, www.astm.org

Brown, S. F., 1996, "Soil Mechanics in Pavement Engineering," Géotechnique, Vol. 46, No. 3, pp. 383-426, http://dx.doi.org/ 10.1680/geot.1996.46.3.383

Camacho-Tauta, J., Cascante, G., Viana da Fonseca, A., and Santos, J. A., 2015, “Time and Frequency Domain Evaluation of Bender Element Systems," Géotechnique, Vol. 65, No. 7, pp. 548-562, http://dx.doi.org/10.1680/geot.13.P.206

Clayton, C. R. I., Khatrush, S. A., Bica, A. V. D., and Siddique, A., 1989, "The Use of Hall Effect Semiconductors in Geotechnical Instrumentation," Geotech. Test. J., Vol. 12, No. 1, pp. 69-76, http://dx.doi.org/10.1520/ GTJ10676J.

Cristelo, N., Glendinning, S., and Pinto, A. T., 2011, "Deep Soft Soil Improvement by Alkaline Activation," Proc. Inst. Civil Eng. - Ground Improve., Vol. 164, No. 2, pp. 73-82, http:// dx.doi.org/10.1680/grim.2011.164.1.1

Cristelo, N., Glendinning, S., Fernandes, L., and Teixeira Pinto, A., 2013, "Effects of Alkaline-Activated Fly Ash and Portland Cement on Soft Soil Stabilisation," Acta Geotech., Vol. 8, No. 4, pp. 395-405, http://dx.doi.org/10.1007/s11440-0120200-9
Cruz, N., 2010, "Modelling Geomechanics of Residual Soils With DMT Tests," PhD dissertation, University of Porto, Porto, Portugal, www.nbdfcruz.com

Davidovits, J., 1991, "Geopolymers-Inorganic Polymeric New Materials,” J. Thermal Anal., Vol. 37, No. 8, pp. 1633-1656.

FGSV, 2009, "Additional Technical Conditions of Contract and Directives for Earthworks in Road Construction," Working Group Earthworks and Foundations, Forschungsgesellschaft für Straßen-und Verkehrswesen, Cologne, Germany.

Grasmick, J. G., Mooney, M. A., Senseney, C. T., Surdahl, R. W., and Voth, M., 2015, "Comparison of Multiple Sensor Deflection Data From Lightweight and Falling Weight Deflectometer Tests on Layered Soil," Geotech. Test. J., Vol. 38, No. 6, pp. 851-863, http://dx.doi.org/10.1520/ GTJ20140172

Jha, A. K. and Sivapullaiah, P. V., 2016, “Gypsum-Induced Volume Change Behavior of Stabilized Expansive Soil With Fly Ash-Lime," Geotech. Test. J., Vol. 39, No. 3, pp. 391-406, http://dx.doi.org/10.1520/GTJ20150017

LCPC, 2000, "Guide Technique pour le Traitement des sols à la Chaux et/ou aux Liants Hydrauliques. Application à la Réalisation des Remblais et des Couches de Forme," Technical Guide for Soils Treated With Lime and Cement, Laboratoire Central des Ponts et Chaussés (LCPC/SETRA), Paris (in French).

Leroueil, S. and Vaughan, P., 1990, "The General and Congruent Effects of Structure in Natural Soils and Weak Rocks," Géotechnique, Vol. 40, No. 3, pp. 467-488, http://dx.doi.org/ 10.1680/geot.1990.40.3.467

Nazzal, M., Abu-Farsakh, M., Alshibi, K., and Mohammad, L., 2007, "Evaluating the LFWD Device for In Situ Measurement of Elastic Modulus of Pavement Layers," 86th Transportation Research Board Annual Meeting, Washington, DC, Jan. 9-13, Transportation Research Board, Washington, DC.

Nusit, K., Jitsangiam, P., Kodikara, J., Bui, H. H., and Leung, G., 2015, "Dynamic Modulus Measurements of Bound CementTreated Base Materials," Geotech. Test. J., Vol. 38, No. 3, pp. 275-289, http://dx.doi.org/10.1520/GTJ20140233

Rao, S. and Acharya, P., 2014, "Synthesis and Characterization of Fly Ash Geopolymer Sand," J. Mater. Civil Eng., Vol. 26, No. 5, pp. 912-917, http://dx.doi.org/10.1061/(ASCE)MT.19435533.0000880

Rios, S., Cristelo, C., Viana da Fonseca, A., and Ferreira, C., 2016a, "Structural Performance of Alkali Activated Soil-Ash Versus Soil-Cement," J. Mater. Civil Eng., Vol. 28, No. 2, 04015125, http://dx.doi.org/10.1061/(ASCE)MT.1943-5533. 0001398

Rios, S., Cristelo, C., Viana da Fonseca, A., and Ferreira, C., 2016b, "Small and Large Strain Behavior of Soil-Geopolymer Versus Soil-Cement," Int. J. Geomech., Vol. 17, No. 3, pp. 1-12, http:// dx.doi.org/10.1061/(ASCE)GM.1943-5622.0000783

Sharma, S. S. and Fahey, M., 2003, "Degradation of Stiffness of Cemented Calcareous Soil in Cyclic Triaxial Tests," Geotech. Geoenviron. J., Vol. 129, No. 7, pp. 619-629, http:// dx.doi.org/10.1061/(ASCE)1090-0241(2003)129:7(619)

Stamp, D. H. and Mooney, M. A., 2013, "Influence of Lightweight Deflectometer Characteristics on Deflection Measurement," Geotech. Test. J., Vol. 36, No. 2, pp. 1-11, http://dx.doi.org/10.1520/GTJ20120034 
Sukmak, P., Silva, P. D., Horpibulsuk, S., and Chindaprasirt, P., 2015, "Sulfate Resistance of Clay-Portland Cement and Clay High-Calcium Fly Ash Geopolymer," J. Mater. Civil Eng., Vol. 27, No. 5, http://dx.doi.org/10.1061/(ASCE)MT.19435533.0001112

Tatsuoka, F., Sato, T., Park, C.-S., Kim, Y.-S., Mukabi, J. N., and Kohata, Y., 1994, "Measurements of Elastic Properties of Geomaterials in Laboratory Compression Tests," Geotech. Test. J., Vol. 17, No. 1, pp. 80-94, http://dx.doi.org/10.1520/ GTJ10076J

van Jaarsveld, J. G. S., van Deventer, J. S. J., and Lukey, G. C., 2002, "The Effect of Composition and Temperature on the Properties of Fly Ash and Kaolinite-Based Geopolymers," Chem. Eng. J., Vol. 89, Nos. 1-3, pp. 63-73, http:// dx.doi.org/10.1016/S1385-8947(02)00025-6

Viana da Fonseca, A., Matos Fernandes, M., and Silva Cardoso, A., 1997, "Interpretation of a Footing Load Test on a Saprolitic Soil From Granite," Géotechnique, Vol. 47, No. 3, pp. 633-651, http://dx.doi.org/10.1680/geot.1997.47.3.633

Viana da Fonseca, A., Carvalho, J., Ferreira, C., Santos, J. A., Almeida, F., Pereira, E., Feliciano, J., Grade, J., and Oliveira, A., 2006, "Characterization of a Profile of Residual Soil From Granite Combining Geological, Geophysical and Mechanical
Testing Techniques," Geotech. Geol. Eng., Vol. 24, No. 5, pp. 1307-1348, http://dx.doi.org/10.1007/s10706-005-2023-Z Viana da Fonseca, A., Ferreira, C., and Fahey, M., 2009, “A Framework Interpreting Bender Element Tests, Combining Time-Domain and Frequency-Domain Methods," Geotech. Test. J., Vol. 32, No. 2, pp. 1-17, http://dx.doi.org/10.1520/ GTJ100974

Viana da Fonseca, A., Rios, S., Amaral, M. F., and Panico, F., 2013a, "Fatigue Cyclic Tests on Artificially Cemented Soil," Geotech. Test. J., Vol. 36, No. 2, pp. 1-10, http://dx.doi.org/ 10.1520/GTJ20120113

Viana da Fonseca, A., Rios, S., and Amaral, M. F., 2013b, "Structural Anisotropy by Static Compaction," Eng. Geol., Vol. 154, pp. 89-97, http://dx.doi.org/10.1016/j.enggeo.2012. 11.012

Wallah, S. E. and Rangan, B. V., 2006, "Low-Calcium Fly Ash-Based Geopolymer Concrete: Long-Term Properties," Research Report GC2, Faculty of Engineering, Curtin University of Technology, Perth, Australia.

Worrell, E., Price, L., Martin, N., Hendriks, C., and Meida, L. O., 2001, "Carbon Dioxide Emissions from the Global Cement Industry," Annu. Rev. Energy Environ., Vol. 26, No. 1, pp. 303-329, http://dx.doi.org/10.1146/annurev.energy.26.1.303 